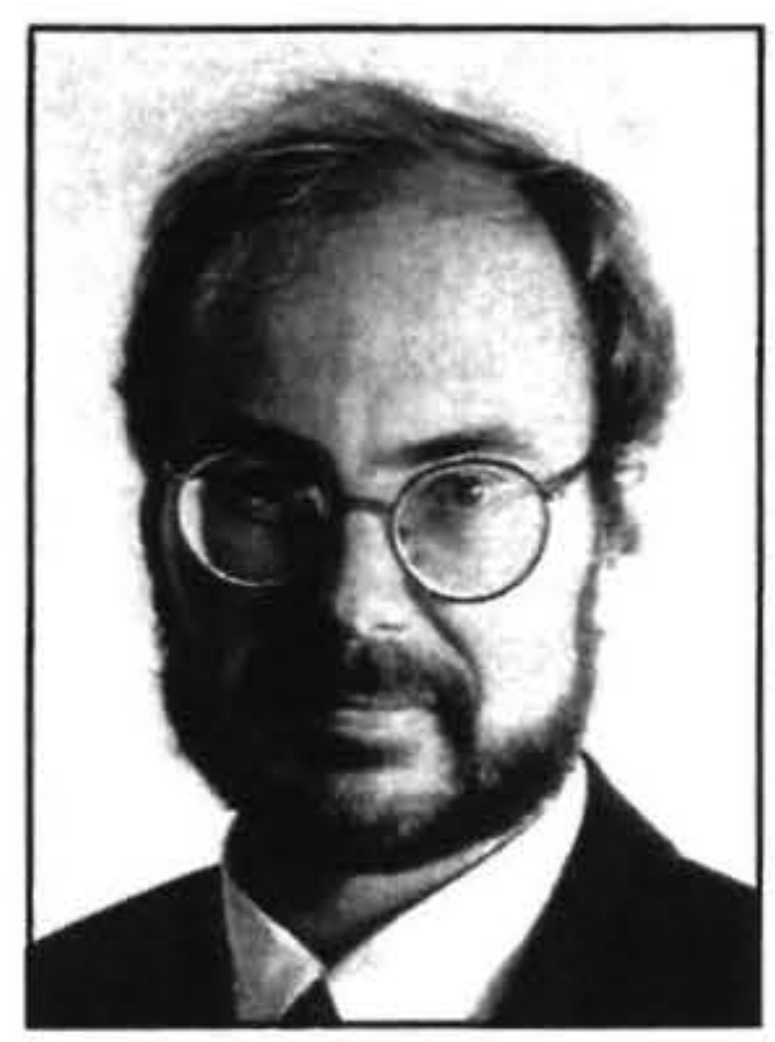

\title{
THE USE OF PRIVATE MEDIATION \\ IN ORGANISATIONAL DISPUTES \\ AND PERSONAL GRIEVANCES - \\ THE EXPERIENCES OF WAIKATO \\ MEDIATION SERVICES
}

\author{
Stephen Hooper \\ Faculty of Law \\ University of Waikato
}

\begin{abstract}
Waikato Mediation Services was formed in 1994. It provides mediation services in number of areas. The vast majority of cases mediated by this organisation have involved private employment mediations. This has meant that the organisation mediates conflicts between management and staff and between managers for a wide range of businesses and organisations. Although each dispute is unique clear patterns have emerged from the large number of cases dealt with so far. This paper examines the factors that have influenced the occurrence of the conflicts and discusses the patterns that have begun to emerge. The conclusion reached is that certain forms of business structure and management practices increase the likelihood of disputes within the workplace. The paper concludes that in order to address workplace disputes it is essential that the context within which the dispute arose be carefully considered before any action is taken by employers.
\end{abstract}

Waikato Mediation Services provides private mediation services throughout the Waikato region for a large number of businesses, social service agencies and 'not-for-profit' organisations. ${ }^{1}$ The vast majority of the cases referred to mediation by these groups involve conflicts between management and staff or between specific staff within the organisations. ${ }^{2}$ These disputes arise mainly in the period during which the employees or managers remain members of the organisations. The mediations arise in the delicate period before the disputes finally escalate into dismissals, resignations and possible personal grievances. ${ }^{3}$ It is generally agreed in the current literature that conflict is an inevitable part of life in organisations ${ }^{4}$ and can be beneficial. ${ }^{5}$ Despite these comments for the vast majority of business managers and staff conflict is a source of stress and tension. This anxiety can be a source of job burnout. ${ }^{6}$

While it must be acknowledged that those disputes which end in mediation represent only a small portion of the disagreements arising within the workplace ${ }^{7}$ these conflicts do provide some guidance in determining the factors that contribute to workplace discord. In particular, these mediations provide some evidence of the implications of corporate culture as one of the catalysts for organisational disputes.

Waikato Mediation Services uses a narrative approach to mediation. As a result our mediators examine some of the underlying influences that contribute to the experiencing of conflict in the workplace. Although there is no single 'cause' of workplace conflict, in a large percentage of the cases mediated the decision-making structure within the organisations and the climate or corporate culture of the workplace have significantly contributed to the employment conflict. ${ }^{8}$
From our experience so far a great deal of care needs to be exercised by managers in reaching decisions on the 'causes' of workplace conflict and their response to the 'problems'. This is particularly important since the failure to address the extent to which the organisational structure has contributed to the problem may be a factor that is taken into account in any subsequent grievance proceedings in determining whether the actions of the employer were justified.

\section{Case study ${ }^{9}$}

Concrete Services is a middle-sized Hamilton Company. It has recently undergone a major change in its direction. This has seen a change in its senior management and a restructuring of its middle management. The restructuring also meant a change in its business premises.

Before the restructuring was carried out the company had used no intermediate staff member between the employees and the board. All staff regularly attended the board meetings to bring proposals and to discuss the issues that directly concerned them. As a result of the restructuring the board appointed a supervisor who attended the board meetings on behalf of all staff. She took proposals and problems to the board and reported back to staff through staff meetings. Although the supervisor's job description changed there was no formal revision of her employment contract.

In addition to the changes to the supervisor's role, the staff were required to work shifts that meant that all staff were not at work at the same time. During periods when the supervisor was not on site the other senior staff carried out her administrative duties. 
The staff had weekly meetings to discuss the problems and issues that had arisen during the week. At one of the staff meetings a major conflict erupted. The supervisor was in the process of discussing the need for additional staff, the budget for the year and the use of performance appraisals for the organisation. One of the senior staff verbally abused the supervisor and refused to accept attempts at further accountability. A major argument ensued and the clash 'got out of hand'. Hearing the problems in the staff meeting the chairperson took the unusual step of joining the staff meeting. Having observed the interactions between the supervisor and the staff member for a brief period of time the chairperson intervened telling the senior staff member to 'shut up'. The staff member told the chairperson that she will not be spoken to like that and stormed out of the room threatening to resign.

The chairperson carried out a review of the 'problem' in a brief meeting with the senior staff member and the supervisor. As a result of the investigation by the chairperson it was felt that this dispute was a reflection of ongoing personality conflicts between the two workers that had led to a deterioration in communication between the two staff. The supervisor advised the chairperson that she was stressed while at work and dreaded the staff meetings. The chairperson formed the view that this conflict was consistent with other problems that had been simmering for some time.

The chairperson and the board discussed the issues in an emergency board meeting and concluded that they must support the supervisor who is ultimately 'just doing her job'. It was felt that the senior staff member had shown herself in the past to be quite challenging to the supervisor's authority. The board decided to give the senior staff member a warning on the basis that her conduct at the staff meeting was 'unacceptable'.

The staff member angered by the decision to issue the warning threatened the board that she would "take them to court'. The board were uncertain whether they could do anything to address the problem and contacted the mediators for assistance.

\section{Review of the issues in the case study}

Although there is never any typical case, this example does include a number of the common features arising in the organisational mediations referred to Waikato Mediation Services. Faced with a conflict within the organisation a large percentage of the managers (and the staff themselves) attribute the problem to personality conflicts between staff or to a global problem referred to as 'poor communication'. Our experience has been that in the vast majority of conflicts these surface issues or flashpoints are just the 'tip of the iceberg'.

Although communication problems do contribute to the dispute it has been our experience that they are rarely the sole source of the difficulty. ${ }^{10}$ Great care must be taken by the managers faced with organisational conflict not to react too quickly based on the surface problem. In particular, the managers must carefully consider the wide range of potential contributing factors including the extent to which the business structure or corporate climate has added to the problem. ${ }^{11}$ It has been our experience in using the narrative mediation approach that the corporate culture or climate of an organisation can play a significant role in the development of workplace conflict.

\section{Narrative and problem solving mediation}

The traditional mediation process relies heavily on problemsolving approaches to negotiation. These approaches arise from the work of the Harvard Negotiation Project and are reflected in Fisher and Ury's (1981) landmark book, Getting to yes. ${ }^{12}$ The traditional process focuses on the 'flashpoints' where the conflict has surfaced. The process searches for 'the cause' of the conflict. The process struggles to address the underlying influences on the conflict including the personal, social and cultural differences that have contributed to the conflict.

The mediation process used by Waikato Mediation Services utilises a narrative approach. The narrative approach differs from the traditional mediation process in a number of important ways. One of the main differences is its greater focus on the multitude of factors that influence the conflict.

In order to explain the narrative concept of conflict it is helpful to use the metaphor of a spider's web. A conflict may be understood as made up of many strands or 'restraints' that prevent the parties from addressing the conflict on their own. ${ }^{13}$ These restraints take the form of habits or patterns of interaction which "hold the conflict in place". The habits or patterns serve to perpetuate the dispute and influence the way in which the parties interpret the acts of others. ${ }^{14}$ The patterns of interaction prevent the parties using their own resources to overcome the conflict.

\section{Conflict and its contributing factors}

There are three major reasons why conflicts occur: person or historical, interactional, and societal and/or cultura. Each will be discussed in turn.

\section{Personal or historical restraints}

These restraints arise out of the personal or historical background of the parties involved in the dispute. In one mediation one of the managers of an organisation acknowledged that one of the contributing factors to an ongoing workplace conflict was his previous experience in a separate organisation. In that situation, which was similar to the current difficulties, he had been dismissed. This previous experience meant that he acted very hesitantly when the problems first arose in the hope that by avoiding the conflict it would 'go away'.

\section{Interactional restraints}

The workplace discord may be contributed to by the differ- 
ences between the parties and the way in which they interact. These interactions establish assumptions or predictions about how individuals would respond in particular situations. ${ }^{15}$ These expectations influence the way in which staff and management interpret experiences.

In one instance what appeared on the surface to be a minor failure to complete timesheets was interpreted by management as evidence of a more general refusal to be accountable. This interpretation arose in a context in which there had been a perceived reluctance by the staff member to disclose important information about the running of her division of the organisation. The manager's decision to confront the employee about this issue had the effect of escalating the problem into a workplace conflict. The matter was subsequently referred to mediation. In the mediation process the employee revealed that her failure to fill out the time sheets was the result of overwork. The employee was willing to be accountable she simply did not have time to complete these administrative duties. In the context of the employer's distrust the delays in completing the timesheets were misunderstood as a more general problem based on the assumptions generated from previous experiences.

\section{Societal or cultural restraints}

In employment mediations the restraints may also arise from or reflect the culture of the workplace or of society as a whole. For example in the narrative mediation process we expressly explore the societal issues of power in employment. This includes the power imbalances created between individual workers and employers through the greater wealth and bargaining power of management. ${ }^{16}$ In one mediation one of the managers expressly acknowledged that he had used his power as a representative of the employer to pressure a staff member to agree to proposed changes to the organisation. He explained that his use of power was the result of pressure being exerted on him by his fellow managers to carry out changes within the organisation as 'efficiently' as possible. The staff member's perceived reluctance to change was seen as an impediment to the 'progress' being made. He apologised for his actions and agreed to be more sensitive to the issues of power in the future. This acknowledgment, explanation and apology was a major turning point in the mediation process.

Each of these strands of the 'web of conflict' is intertwined so that a problem in one area may contribute to other problems. In employment disputes it is not uncommon for a loss of trust between employees to contribute to the restriction of communication between the parties. This lessening of communication in turn increases the level of distrust.

To deal with the conflict the parties must endeavour to identify the restraints and find alternate ways of dealing with the situation. It has been our experience that there are invariably a number of aspects of the work relationship between the parties that stand apart from the web of conflict. This includes times when the parties have been able to work together. In the course of the narrative process the parties are asked to explore and account for these contradictions to the 'web of conflict'. In exploring these contradictions the parties are invited to consider whether these contradictions represent a preferred work relationship. They are also invited to contemplate how they can build on these contradictions so that these 'exceptions' have a greater part to play in the work relationship of the two parties.

The narrative process enables us to explore with the parties a wider range of factors contributing to the occurrence of the conflict. It enables us to look beyond the flashpoints or surface issues in order to explore some of the personal and cultural themes that have influenced the conflict. One of the factors exposed which increases the risk of conflict is the corporate climate or culture of the workplace.

\section{Corporate or business culture or climate}

David states that there are a number of inbuilt factors that affect a businesses' ability to effectively implement systems to manage disputes. ${ }^{17}$ Similar factors also increase the risk of conflict and influence the way in which an organisation deals with the conflict once it arises. The following factors have been identified from the mediations completed so far: ${ }^{18}$

1. A business's hierarchical structure that limits communication between management and staff.

2. An entrenched culture of managerial decision-making as opposed to consensus decision-making.

3. A climate that promotes independence and self-reliance at the expense of 'teamwork' or 'working together'.

4. A culture of avoiding or suppression of conflict.

These aspects of corporate culture provide a shared social structure within the workplace that influences the way in which staff and managers respond to a wide variety of experiences and interactions including conflict. ${ }^{19}$ The culture provides norms for dealing with conflict that govern the routine or habitual conflict management practices. ${ }^{20}$ They can also have the effect of increasing the likelihood of conflict within an organisation.

\section{Hierarchical business structures}

In a large percentage of the cases referred to Waikato Mediation Services the organisations have a hierarchical business structure using senior managers and middle managers or supervisors. This structure is referred to by Mastenbroek as a 'High vs Middle vs Low' organisational power structure. ${ }^{21}$ The effect of the business structure is to place the supervisor in the invidious position of the person caught in the middle. Left in this difficult role supervisors often find themselves in a 'role ambiguity', 22 having difficulty balancing their role as a representative of management while remaining a member of staff. 23

In the case study the difficulties inherent in the use of supervisors were intensified by the absence of any formal contract that set out the terms and conditions of the supervisor's position. All of the staff interviewed, including the supervisor herself, noted that one of the key problems in this 
case was the lack of definition of the supervisor's position. The lack of definition of her role meant that a large number of issues were taken back to the board rather than being decided at a staff level. One of the key problems lay in the uncertainty as to how much could be spent without authorisation by the board. The supervisor was seen by the other staff as blocking even the most trivial of decisions. In this instance this was because the supervisor was unsure whether she could authorise the expenditure. This created an added stress on the working relationship between the supervisor and the other staff.

Mastenbroek notes that it is important to ensure that the communication between the middle management and the senior managers and the subordinates is clear and that there is the giving and receiving of sufficient information. ${ }^{24}$ In the case example the communication lines had begun to collapse with the combination of shift work and the ending of the staff attendance at board meetings. This created a real resentment between the staff and management. This was heighten by the changes to the composition of Board. The staff had no real work history or trust in the new board that would have assisted them to address the conflict. The problem escalated with the introduction of performance appraisals that were viewed with suspicion by the staff. This meant once again that the supervisor became the focus of discontent.

When the issue was discussed with the board they acknowledged that the structure had not worked as effectively as had been expected. When we enquired as to why the structure was put in place the reason given was that 'this the way things have been done around here for some time'. By getting the Board to become actively involved in the mediation process we were able to ask what they considered were the advantages of the systems that they had used in the past as a basis for the management of the organisation. In particular, they were asked whether they saw any benefits or problems in a hierarchical business structure? Did they see any advantages or disadvantages in a more horizontal structure?

Considering their past experience and discussions with the staff in a joint meeting, the management acknowledged that adjustments were needed to the organisational structure. The managers were able to see how the structures had contributed to the organisational problems and were prepared to review the structure as part of a wider process of strategic planning. It was agreed that this process should take place in consultation with the staff.

\section{Culture of managerial decision making rather than consensus decision making.}

Folger identifies four important organisational 'climates' that influence the patterns of interaction between staff and management. ${ }^{25}$ One of the climates identified by Folger revolves around dominance and authority relations that deal with the distribution of power and decision-making within the organisation. ${ }^{26}$ This business climate concentrates power and decision-making almost exclusively in the hands of management. As a consequence there is an expectation that management is responsible for making decisions and deci- sively solving problems. ${ }^{27}$

Our experience in industrial mediation indicates that this culture causes particular difficulties during periods in which change is being initiated in the workplace. In the case example there were major changes to the management team and consequent changes to the management style. This lead to greater accountability and performance reviews for all staff. These changes took place in a context of changing premises and the use of shift work. These decisions as to the direction and manner of operation of the organisation were made without consulting the staff. ${ }^{28}$ This created resentment amongst the staff and a view that their input and work were not recognised or respected.

The outcome of the mediation was a recognition that the staff had a valid and vital role to play in planning the direction of the organisation. This recognition meant that the organisation took important steps towards a greater level of consensus decision-making within the organisation.

\section{Independence and self reliance at the expense of 'teamwork' or 'working together'}

During the course of the industrial mediation process one of the issues explored by us as mediators is "What are your goals and aims at your workplace?" and "What type of relationships with your fellow workers is preferable to you?" Almost invariable the response from staff and management to this enquiry has been a desire to work together and explore the use of team work. This provides not only a useful metaphor enabling the parties to move forward it also reflects another problem in the corporate culture of the workplace. The problem is one in which staff are encouraged to be self-reliant and independent.

Folger describes this as an individualistic orientation, one in which the members of the organisation do not believe that they are dependent on one another. ${ }^{29}$ These attitudes encourage employees to maintain distance from one another and conclude that their roles are unrelated. This is reflective of a wider societal cultural view that promotes independence over interdependence. ${ }^{30}$

To provide an example, a conflict arose in a social-service agency between management and the counsellor and social worker for the agency. The staff member had been placed in sole charge of one division of the agency. She was solely responsible for all aspects that division, from funding applications to the provision of counselling and social services. She completed this on her own even though there was funding to employ further staff. Since she was the only paid employee she became convinced that management expected that "if a job was worth doing, I have to do it myself". As a result she did not to delegate any of the work tasks to volunteers engaged to assist. She collected furniture and food, packed food parcels and answered the telephones for the organisation as well as completing her heavy schedule of counselling and social work duties. Not surprisingly she became greatly overworked. This overwork contributed to the poor performance of her designated tasks. Once the 
organisation began to address the performance issues a conflict arose between her and her managers that could only be addressed in mediation.

During the mediation process we examined the cultural expectation of self reliance and how this workplace and societal expectation had influenced the employee's actions. The employee and the managers of the organisation recognised that these expectations were encouraging her to work long hours that were affecting both her home and work life. These long hours were now contributing to performance problems at work. Having discussed these expectations and how these assumptions were affecting her it was decided that the division of the agency needed to be restructured. Extra staff were employed which allowed the counsellor to concentrate on her designated duties. She was assured by management that they did not expect her to accept responsibility for all of the tasks in the workplace. The employee was able to return to a workplace where she did not have to do everything. In this case she returned to a workplace without conflict.

There needs to be an understanding that employees and managers are mutually dependent and part of a larger whole. Rather than promoting independence and even competition within an organisation, it is clearly preferable to promote teamwork. ${ }^{31}$ A failure to promote increased team work can contribute to stress and overwork by staff and potentially lead to conflict within the organisation.

\section{A culture of avoidance or suppression of conflict}

Within some organisations there remains a culture that confrontation is negative. Staff and management dislike it, seek to avoid it and when involved seek to stop it. This can lead employees to believe that those who confront issues 'get fired', that disagreement is a sign of disloyalty and that conflict in a work place is a sign of dysfunction or poor management. ${ }^{32}$ This corporate climate revolves around the assumption that conflict is negative and that it is the role of management to minimise conflict. ${ }^{33}$

It has been our experience that conflict must be addressed as soon as possible regardless of the apprehension that this may create. Except in relation to minor issues the avoidance or suppression of conflict can be more dangerous than facing the issues directly. Tjosvold suggests that it is "conflict avoidance and the failure to develop an organization equipped to manage it, not conflict itself,... [that causes disruption within organisations]"34

In one instance a dispute arose between two staff members in an organisation. In accordance with a consistent pattern of conflict avoidance the employer attempted to pacify the staff members without actually addressing their concerns. The response of one of the staff members was to speak to the local newspaper. The problem quickly escalated. The damage done through the avoidance of the conflict could not be undone in the mediation process. The parties had become inflexible and too firmly entrenched to deal with the issues through mediation.

It is preferable to deal with the issues in dispute as early as is possible rather than allow the conflict to be avoided or suppressed in the hope that it will go away. It has been our experience that the conflict will either escalate or resurface in another form at a later stage. Once the problem escalates or resurfaces it is more difficult to address the underlying influences contributing to the conflict as the parties become more entrenched in positions or overlook the original catalyst for the problem.

\section{Why should the employers be concerned?}

The principles of natural justice require that the employers take into account a number of factors before any employee is dismissed or any action is taken to their detriment. One of the factors that must be taken into account is the extent to which the employer is in some way responsible for the situation that developed. ${ }^{35}$ In the mediations that are referred to in this article it is important to note that the corporate culture has contributed significantly to the workplace conflicts that arose. It is dangerous for management to ignore the corporate culture of the organisation in reaching a decision to take action against an employee. By ignoring the business context there is a risk that the Employment Tribunal or the Employment Court will find that the employer has failed to adequately consider all of the relevant factors before deciding what action to take.

\section{Conclusion}

In the particular case study, the mediation process ended with a facilitated meeting between all of the staff and the management of the organisation. During the course of the meeting we explored how the changes in the business structure had influenced the conflict. It was resolved that during the strategic planning process the organisation would search for ways to change the culture of the organisation. It was intended to move away from a hierarchical business structure in which management was solely responsible for decision-making towards a horizontal structure which increased the consultation with staff over decisions affecting the workplace. This strategic planning process was to take place in consultation with all staff. There were no further "outbreaks" of conflict within the organisation.

Management and staff need to be aware of the corporate cultures that operate within their organisations and how these contribute to conflict. In dealing with conflict in the workplace managers and staff ignore the context of the dispute at their peril. The culture or climate of the organisation should be carefully considered before any action is taken to address the conflict.

\section{Further research}

In identifying the effect of the corporate culture on conflict within an organisation we are conscious that we have not explored the issue - what steps can be taken to identify these issues in organisations? Once identified what steps can be 
taken to deal with these "climatic conditions" within an organisation? Both of these issues require further research.

It is also necessary that further research be completed exploring the extent to which private mediation is used in New Zealand. It is essential to review the effectiveness of early intervention in organisational disputes as apposed to mediations take place after the grievance has already occurred. Where there have been delays in instituting the mediation process it has been our experience that the parties have developed fixed viewpoints that limit the options available to bring the conflict to an end. What are the advantages and disadvantages of private mediation and the Employment Tribunal Process? What adjustments need to be made to the Tribunal process to address the limitations?

\section{Notes}

1. While some articles have been written on the use of mediation in the Employment Tribunal, little has been written on the use of private mediation. Further research is clearly essential to record the extent to which mediation is being used outside the Tribunal. For a review of the use of mediation within the Tribunal see Goddard (1993: 47-51).

2. This paper will concentrate on the use of private mediation in conflicts between individuals examining interpersonal and small group conflict. Waikato Mediation Services has also been involved in conflict within boards and between managers. This aspect of our work is not explored in this paper.

3. The writer has been involved in mediation which arise in the period after the initiation of personal grievance claims.

$$
\text { 4. Pondy (1992: 257-261, 257.) }
$$

5. Folger, Poole, and Stutman (1993: 1) ; Deutsch (1987: 38 49); Rahim (1985: 3); Tjosvold, D. (1991:3).

6. Rahim (1990). It is also a potential source of economic loss for the organisations themselves. This is reviewed in Turkington, D.J. (1976).

7. A point noted in Kolb and Putnam (1992:1-31, 15).

8. This confirms the findings of Rahim (1985 supra $\mathrm{n} .2$ at $\mathrm{p}$. 50).

9. Although this is based on two real life examples the case study has been extensively changed. All names and business types have been modified to protect the confidentiality of the parties involved.

10. This confirms the view of Folger, Poole, and Stutman supra n. 2 at p. 5.

11. The case example also serves to highlight the fact that at times the management of an organisation may not be the best people to resolve a conflict particularly where they have in some way contributed to the escalation of the dispute. This confirms the view expressed by Kolb and Putnam supra n. 8 p. 12

12. Fisher, Ury, and Patton, (1991).

13. White, (1989: $85-99,86)$.

14. It is in some ways similar to the idea of 'perspectivism' used by Folger, Poole, and Stutman supra n. 2 p. 40.

15. Folger, Poole, and Stutman (1993:71)

16. Turkington (1976:19).

17. David (1994: 26-38, 27).

18. Some of these factors are consistent with the elements identified by David (1995)

19. Ibid., at p. 16 .

20. Ibid., at p. 17.

21. Mastenbroek (1993:70).

22. Ibid. p. 70.

23. Roethlisberger (1944:283-98).

24. Mastenbroek (1993:72).

25. Folger, Poole, and Stutman supra n. 2 p. 159-163.

26. Ibid., at p. 160 .

27. Tjosvold (1991:10).

28. This has been identified as a potential source of problems in organisations. See Rahim (1990:19).

29. Folger, Poole, and Stutman (1993:20).

30. Freedman and Combs(1993:19-40).

31. Mastenbroek (1993:37).

32. Watkins (1986:26-7).

33. Tjosvold 1991 supra n. 2 at p. 2. This reflects a 'classic view' of conflict, that conflict is detrimental to organisational efficiency and therefore should be minimised Rahim (1985:4-6).

34. Tjosvold (1991:5).

35. See for example Trotter $v$ Telecom (1994) 98, 243 at 98,244 . 


\section{References}

David, J. 1994 Designing a dispute resolution system Commercial Dispute Resolution Journal 13:26-38.

Deutsch, M. 1987 A theoretical perspective on conflict and conflict resolution. In Sandole, D.J.D. and Sandole-Staroste, I. (eds) Conflict management and problem solving: interpersonal to international applications New York, New York University Press.

Fisher, R, Ury, W and Patton, B 1991 Getting to yes (2nd ed) London, Business Books.

Folger, J.P., Poole, M.S. and Stutman, R.K. 1993 Working through conflict strategies for relationships, groups and organizations New York: Harper Collins College Publishers (2nd Edition).

Freedman, J. And Combs, G. 1996 Narrative therapy the social construction of preferred realities New York, W.W. Norton \& Company, Inc.

Goddard, T.G. 1993 Mediation - past endeavours, future trends Employment Law Bulletin 47-51.

Kolb, D.M. and Putnam, L.L. 1992 Introduction the dialectics of disputing. In Kolb, D.M. and Bartunck J.M. Hidden (eds) Conflict in Organizations Newbury Park, California Sage Publications Inc,1-31.

Mastenbroek, W.F.G. 1993 Conflict management and organization development (an expanded edition) Chichester: John Wiley \& Sons Ltd.

Pondy, L.R. 1992 Reflections on organizational conflict 13 Journal of Organizational Behavior 13:257-261, 257.

Rahim, M.A. 1985 Managing conflict in organizations New York, Praeger.

Rahim, M.A. 1990 Moderating the effects of hardiness and social support on the relationships of conflict and stress to job burnout and performance. In Rahim A.F. (ed) Theory and research in conflict management New York, Praeger, 414.

Roethlisberger, FJ 1944 The foreman: master and victim of double talk Harvard Business Rev, 383-98.

Sandole, D.J.D. and Sandole-Staroste, I. (eds) Conflict management and problem solving: interpersonal to international applications New York, New York University Press.

Tjosvold, D. 1991 The conflict-positive organization stimulate diversity and create unity Reading, Massachusetts, Addison-Wesley Publishing Company.

Trotter v Telecom (1994) 4 NZELC (Digest) 98, 243 at 98,244 .
Turkington, D.J. 1976 The economic effects of industrial conflict Occasional Papers in Industrial Relations (no. 19) Wellington Industrial Relations Centre.

Turkington, D.J. 1976 A conceptualisation of industrial conflict Occasional Papers in Industrial Relations (No. 17) Wellington Industrial Relations Centre.

Watkins, K. 1986 When co workers clash Training and Development Journal April:26-27.

White, M. 1989 Negative explanation, restraint, \& double description a template for family therapy. In White, M. Selected Papers Adelaide, Dulwich Centre Publications, 85-99.

\section{Author}

Stephen Hooper is a lecturer in Dispute Resolution in Faculty of Law, University of Waikato, Private Bag 3105, Hamilton.Email: shooper@waikato.ac.nz 